\title{
Effectiveness of Short-term Dynamic Psychotherapy versus Sertraline in Treatment of Social Phobia
}

\author{
Mehryar Nader-Mohammadi Moghadam ${ }^{1}$; Mohammad-Kazem Atef-Vahid ${ }^{1,{ }^{*}}$; Ali-Asghar \\ Asgharnejad-Farid ${ }^{1}$; Amir Shabani ${ }^{1}$; Fahimeh Lavasni ${ }^{1}$ \\ ${ }^{1}$ Tehran Institute of Psychiatry, Tehran University of Medical Sciences Tehran, IR Iran \\ ${ }^{*}$ Corresponding author: Mohammad-Kazem Atef-Vahid, Tehran Institute of Psychiatry, Tehran University of Medical Sciences, Tehran, IR Iran. Tel: +98-2166506862, Fax: +98-2166506862, \\ E-mail: kazemv@yahoo.com
}

Received: October 25, 2014; Revised: November 22, 2014; Accepted: February 7, 2015

\begin{abstract}
Background: A few studies on short-term psychodynamic approach have been conducted on social phobia.
Objectives: In this study, the effectiveness of short-term psychodynamic psychotherapy on the treatment of social phobia has been compared to the effectiveness of sertraline and waiting list.

Materials and Methods: In this randomized-controlled trial study, 13 male students were treated with short-term dynamic psychotherapy (McCullough method) lasting 25 sessions, 11 students received sertraline for 12 weeks, and 14 students, as the waiting list, received no intervention for 8 weeks. Participants completed the Social Phobia Inventory (SPIN) as primary efficacy variable 4 times, and were rated with Clinical Global Impression scale (CGI) and Global Assessment of Functioning (GAF) as secondary efficacy variables. The data were analyzed with analysis of variance (ANOVA), analysis of covariance (ANCOVA), general linear model repeated measures analysis of variance and Fisher exact test.

Results: ANCOVA showed significant differences between groups based on SPIN scores $(\mathrm{F}=23.51$, Sig. $=0.001)$ and Bonferroni test, as post hoc compression, showed means of both short-term dynamic therapy and sertraline therapy groups were significantly different from waiting list mean (STDP-WL: ${ }^{x}$ dif $=15.76$, Sig. $\left.=0.001\right),($ MED-WL: $\overline{\mathrm{X}}=15.91$, Sig. $=0.001)$. Mean of SPIN scores was not significantly different between short-term dynamic psychotherapy and pharmacotherapy groups. In both treatment groups, means of SPIN scores significantly decreased in posttest, but not in waiting. These results repeated with GAF and CGI scores.

Conclusions: The results indicated that short-term dynamic psychotherapy sertraline are effective in decreasing social phobia symptoms and were superior to control group.
\end{abstract}

Keywords: Phobic Disorders; Psychotherapy, Psychodynamic; Sertraline

\section{Background}

Social phobia is one of the most prevalent psychiatric disorders (1-5) and usually begins at young ages, between 14 and 34 years (2, 6-9). Studies have shown that on average people with severe symptoms have suffered from this disorder for 20 years $(10,11)$. Social phobia is a durable disorder even after years of treatment $(12,13)$. More than $80 \%$ of people who suffer from social phobia have another comorbid disorder $(14,15)$. This disorder causes more pervasive problems than other anxiety disorders (15-18). Retrospective and prospective epidemiological studies suggest that social phobia can create confusion and deep problems in life, including problems in school and college achievement $(2,11,18)$ and can disrupt job performance $(15,16)$ and social development $(2,15,16)$. Studies have shown that regardless of the cost of comorbidities, the annual per capita costs of social phobia is $\$ 6100$ (19). A wide range of therapies has been introduced for the treatment of social phobia (20). Pharmacotherapy (21), psycho-education, cognitive-behavioral therapy (22), be- havior therapy (23) and psycho-analytic psychotherapy are common treatment methods for social phobia (24).

Effectiveness of different types of drugs has been studied in the treatment of social phobia (21). Selective serotonin reuptake inhibitors (SSRI) are first-line treatments of social phobia (Effect size of 0.65 with $95 \%$ confidence interval, 0.81 to 0.50$)$ (20). Effectiveness of sertraline in several studies has been confirmed too (25-29).

Some studies have shown that social phobia or social anxiety disorder may respond to cognitive and behavioral therapy very slowly (30) and response to treatment with Cognitive behavioral therapy (CBT) for the treatment of social phobia-about $50 \%$-is not satisfactory (31, 32). Also it seems that relaxation training alone is ineffective for the treatment of social phobia (33).

Although the effectiveness of psychodynamic psychotherapy on the treatment of several disorders has been studied, Fonagy (2005) stated "there is no controlled research study for two common problems; anxiety and

Copyright (C) 2015, Mazandaran University of Medical Sciences. This is an open-access article distributed under the terms of the Creative Commons Attribution-NonCommercial 4.0 International License (http://creativecommons.org/licenses/by-nc/4.0/) which permits copy and redistribute the material just in noncommercial usages, provided the original work is properly cited. 
social phobia" (34). Blanco and colleagues' study (2003) also confirmed the absence of empirical studies on the effectiveness of psychodynamic psychotherapy on the treatment of social phobia (20).

McCullough's approach, called Affect Phobia Treatment (APT), is one of the well-known short-term dynamic psychotherapies (35). McCullough has developed a specific manual for her therapeutic approach. According to her, facilitating the occurrence of emotions and leaving defense mechanisms ultimately leads to the relief of symptoms of the disorder. APT focuses on resolving emotional conflicts and the underlying psychodynamic framework. Three techniques are used in APT: affect restructuring, defense restructuring, and self/other restructuring (36). Affect restructuring consists of two parts. First, the therapist helps the patients to slowly become more related with their own internal emotional experiences. Second, they learn how to express emotions in interpersonal relationships. Defense restructuring consists of two parts. First of all, the therapist helps the patients to recognize their defenses against emotional problems. Then, the patients become familiar with the advantages and disadvantages of using these defenses and gradually give them up. Restructuring the sense of self and others consists of two parts. First, the individual's relationship with oneself is guided toward creating more positive feelings. Second, person's communications with others are guided to create satisfactory and good mutual relations (37).

APT is effective in patients with cluster $C$ personality disorders $(38,39)$. Dehghani's study in Iran has shown that this treatment is effective in love failure (40), but the effectiveness of this method has not been evaluated in the treatment of anxiety disorders (41).

\section{Objectives}

With regard to inadequate information about effectiveness of psychodynamic approaches in treating social phobia and relatively low impact of other treatment approaches, also considering the high prevalence and extensive damage of social phobia, the aim of this study was to compare the effectiveness of McCullough's shortterm dynamic psychotherapy versus medication (sertraline) in treating social phobia.

\section{Materials and Methods}

This study used a quasi-experimental design with pretest-posttest repeated measures in multiple groups. The data were gathered from 22 December 2011 to 19 June 2012. The sample consisted of 45 male students of Tehran University who met the criteria for social phobia. The inclusion criteria were as follows: SPIN score $\geq 24$, age between 18 to 50 years, and meeting the DSM-IV-TR criteria for social phobia based on SCID. The exclusion criteria were as follows: being psychotic, or obsessive-compulsive; having bipolar, or organic brain disorders; drug and alcohol dependency; having impulse control disorders, cluster A and B personality disorders, active disorder on axis III, a history of suicidal thoughts and actions, a history of violent behavior; being on psychotropic medications or receiving psychotherapy for the treatment of social phobia during the last 6 months, or experiencing the symptoms of social phobia as part of other psychiatric disorders. The participants were randomly assigned into 3 groups:1- psychotherapy (STDP), 2- medical therapy (MED) and 3- waiting list (WL).

The inclusion and exclusion criteria were evaluated by the demographic characteristic questionnaire and the Structural Clinical Interview for DSM-IV (SCID-I, II) (42). The Social Phobia Inventory (SPIN) (43) was used for the primary effectiveness variable, Global Clinical Impression-Severity and Improvement (CGI-S, CGI-I) (44) and Global Assessment of Functioning (GAF) (45) were used for the secondary effectiveness variables. All instruments have acceptable validity and reliability (SPIN: $r>0.80$, CGI: $r>0.65$, GAF: $r>0.69$, and SCID: $r>0.90$ ). Diagnostic interviews were conducted by a psychiatrist.

Patients in the STDP group received 21 individual psychotherapy sessions, twice per week, in addition to 4 initial and posttest evaluation sessions. The therapy sessions were conducted using McCullough's manual. Members of the MED group received pharmacotherapy (sertraline) for 12 weeks. Patients in the WL group received no intervention. However, after the waiting period, they received preferred treatment services. Each group was evaluated 4 times during the study.

Statistical analyses were performed using SPSS version 16. Differences between groups in pretest and posttest scores of SPIN, GAF, CGI-I, CGI-S were assessed using analysis of variance, analysis of covariance, and Bonferroni as Post hoc test. Differences created during the T1, T2, T3, and T4 evaluations were analyzed using General Linear Model repeated measures analysis of variance.

Remission was defined as CGI-I $=1$ and SPIN $<16$. Response to treatment was defined as CGI-S $\leq 2$ and 50\% reduction in SPIN scores at posttest (T4) compared to the baseline(T1) scores (46). Differences between the groups in the percentages of the patients showing remission and responding to treatment were determined using Fisher exact test. The effect size was calculated using pretests and posttest mean scores and was evaluated by Cohen's scale (Figure 1).

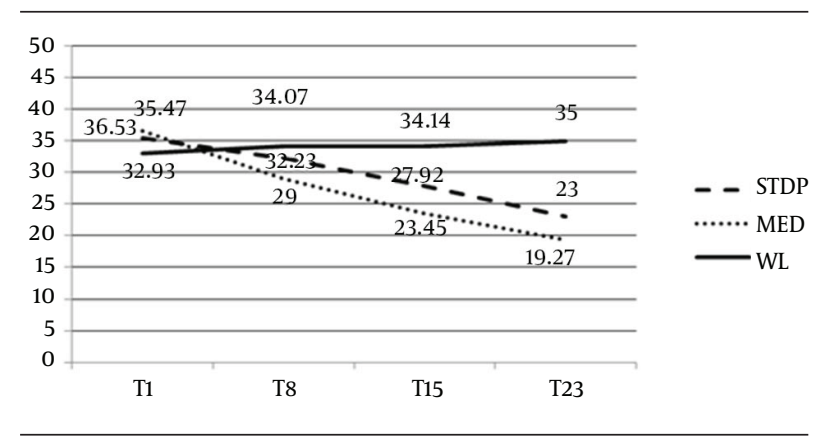

Figure 1. SPIN Scores in the Assessments of T1, T2, T3, T4 
Nader-Mohammadi Moghadam M et al.

\section{Results}

The demographic characteristics of the study sample are presented in Table 1. No significant differences were observed among the groups regarding the demographic variables, history of psychiatric problems, and drug use. Means and standard deviations of SPIN, GAF, and CGI-S scores at pretest and posttest evaluations for each group are presented in Table 2 . There were no significant differences between the groups in terms of the pretest mean scores of SPIN ( $\mathrm{F}=0.737, \mathrm{P}<0.485)$, CGI-S $(\mathrm{F}=1.35, \mathrm{P}<$ $0.269)$, and $\mathrm{GAF}(\mathrm{F}=2.571, \mathrm{P}<0.88)$.

ANCOVA showed significant differences between the three groups regarding the posttest scores of SPIN (F = 23.51, P $<0.001$ ). Pretest scores were considered as covariate. Bonferroni revealed that the posttest scores of STDP and MED were significantly different from WL scores

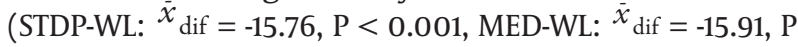
$<0.001)$. However, no significant difference was noted be-

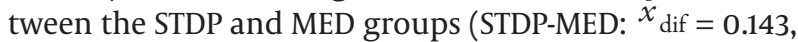
$\mathrm{P}<0.313)$. Similar findings were obtained regarding CGI-S, CGI-I and GAF mean scores (Table 3).

Repeated measures ANOVA revealed no significant differences regarding various assessments of SPIN between STDP and MED (within group effect, time group: F $=0.423, \mathrm{P}=0.658$, between group effect, time group: $\mathrm{F}=$ $0.219, \mathrm{P}=0.645$ ). But the measures of both groups were significantly different from WL (within group effect, time group: $\mathrm{F}=14.86, \mathrm{P}<0.01$, between group effect, time group: $\mathrm{F}=25.28, \mathrm{P}<0.01)$.

The numbers and percentages of the patients who had responded to treatment and had shown remission in each group are presented in Table 4 . There were no significant difference among the groups regarding the number and percentages of the patients who had responded to treatment and showed remission. The effect sizes of interventions were calculated by comparing the pretest and posttest mean scores based on Cohen's scale (Table 5).

\begin{tabular}{|c|c|c|c|}
\hline Group & STDP & MED & $\mathbf{W L}$ \\
\hline \multicolumn{4}{|l|}{ Education } \\
\hline Masters & $3(20)$ & $5(33)$ & $4(26.7)$ \\
\hline Bachelor & $12(80)$ & $10(67)$ & $11(73.3)$ \\
\hline \multicolumn{4}{|l|}{ Marital status } \\
\hline Single & $15(100)$ & $14(93.34)$ & $15(100)$ \\
\hline Married & $0(0)$ & $1(6.66)$ & $0(0)$ \\
\hline \multicolumn{4}{|l|}{ Employment } \\
\hline Employed & $1(6.66)$ & $0(0)$ & $0(0)$ \\
\hline Unemployed & $14(93.34)$ & $15(100)$ & $15(100)$ \\
\hline \multicolumn{4}{|c|}{$\begin{array}{l}\text { Previous psychiatric } \\
\text { problems }\end{array}$} \\
\hline Having & $2(13.3)$ & $3(20)$ & $1(6.7)$ \\
\hline No & $13(86.7)$ & $12(80)$ & $14(93.3)$ \\
\hline Age & $24.26 \pm 1.5$ & $24.62 \pm 2.8$ & $24.47 \pm 1.6$ \\
\hline
\end{tabular}

Table 2. The Means and Standard Deviations of Pretest and Posttest Scores for Each Group

\begin{tabular}{lccc}
\hline Group & STDP & MED & WL \\
\hline SPIN & & & \\
Pretest & $35.47 \pm 8.56$ & $36.53 \pm 9.13$ & $32.93 \pm 7.22$ \\
\hline Posttest & $23 \pm 10.39$ & $19.27 \pm 8.86$ & $35 \pm 7.22$ \\
\hline GAF & & & \\
\hline Pretest & $59.06 \pm 6.94$ & $63.46 \pm 5.96$ & $64.07 \pm 6.4$ \\
\hline Posttest & $71.46 \pm 6.85$ & $70.72 \pm 9.23$ & $62.64 \pm 7.76$ \\
\hline CGI-S & & & \\
\hline Pretest & $4.47 \pm 0.990$ & $3.93 \pm 0.884$ & $4.20 \pm 0.775$ \\
\hline Posttest & $3.31 \pm 1.43$ & $2.73 \pm 1.34$ & $4.43 \pm 0.851$ \\
\hline
\end{tabular}

a Abbreviations: CGI-S, Clinical Global Impression-severity; GAF, Global Assessment of Functioning; MED, medication; SPIN, Social Phobia Inventory; WL, waiting list.

b Data are presented as mean $\pm S D$.

Table 3. Results of ANCOVA and the Post Hoc Comparisons (Bonferroni) for Posttest Mean Scores on the CGI-S, CGI-I and GAF ${ }^{\text {a, }} \mathrm{b}$

\begin{tabular}{|c|c|c|c|}
\hline Scale & $\begin{array}{l}\text { CGI-S }(\mathrm{F}=11.54) \\
(P<0.001)\end{array}$ & $\begin{array}{c}\text { CGI-I }^{\mathrm{C}}(\mathrm{F}=16.08) \\
(\mathrm{P}<0.001)\end{array}$ & $\begin{array}{c}\text { GAF }(F=19.97), \\
(P<0.011)\end{array}$ \\
\hline \multicolumn{4}{|l|}{ Group } \\
\hline STDP-MED & $0.025(0.98)$ & $-0.035(0.293)$ & $3.22(0.510)$ \\
\hline STDP-WL & $-1.56(0.001)$ & $-1.37(0.001)$ & $13.75(0.001)$ \\
\hline MED-WL & $-1.58(0.001)$ & $-1.344(0.001)$ & $10.52(0.001)$ \\
\hline \multicolumn{4}{|c|}{$\begin{array}{l}\text { a Abbreviations: CGI-S, Clinical Global Impression-severity; CGI-I, } \\
\text { Clinical Global Impression-improvement; GAF, Global Assessment } \\
\text { of Functioning; MED, medication; STDP, short-term dynamic } \\
\text { psychotherapy; WL, waiting list. } \\
\text { b Data are presented as }{ }^{\bar{x}} \text { dif (P value). } \\
\text { c CGI-I posttest scores were analyzed using ANOVA. }\end{array}$} \\
\hline
\end{tabular}

Table 4. Response to Treatment and Remission Rate in Intervention Groups ${ }^{\mathrm{a}, \mathrm{b}}$

\begin{tabular}{lcccc}
\hline & $\begin{array}{c}\text { Response to } \\
\text { Treatment }\end{array}$ & $\begin{array}{c}\text { Fisher } \\
\text { Exact Test }\end{array}$ & Remission & $\begin{array}{c}\text { Fisher } \\
\text { Exact Test }\end{array}$ \\
\hline STDP & $4(30.76)$ & $\mathrm{P}=0.675$ & $2(15.38)$ & $\mathrm{P}=1$ \\
MED & $5(36.11)$ & & $2(18.18)$ & \\
\hline
\end{tabular}

a Abbreviations: MED, medication; STDP, short-term dynamic psychotherapy.

Remission: CGI-I $=1$ and SPIN $<16$. Response to treatment: CGI-S $\leq 2$ and 50\% reduction in SPIN T4 scores than baseline.

\begin{tabular}{lccc}
\hline \multicolumn{4}{l}{ Table 5. Effect Sizes of Interventions Based on Cohen's d ${ }^{\mathrm{a}, \mathrm{b}}$} \\
\hline Scale & SPIN & CGI-S & GAF \\
\hline Group & & & \\
STDP & 1.19 & 0.811 & 1.81 \\
MED & 1.94 & 0.895 & 0.79 \\
WL & 0.286 & 0.270 & 0.184 \\
\hline
\end{tabular}

a Abbreviations: CGI-S, Clinical Global Impression-severity; GAF, Global Assessment of Functioning; MED, medication; STDP, short-term dynamic psychotherapy; WL, waiting list.

b Cohen's d: 0 - 0.2, small; 0.3 - 0.5, medium; 0.6- 0.8, large; > 0.9, very large. 


\section{Discussion}

Based on the results of the study, both short-term dynamic psychotherapy and treatment with sertraline were effective in significantly reducing the symptoms of social phobia as compared to the waiting list. These results are consistent with the findings of Bogels (47), and considering general psychiatric symptoms are in line with Crits-Christoph (48), Leichsenring $(49,50)$, and Lewis (51) studies. Both shortterm psychodynamic and pharmacological interventions were almost equally effective in improving the overall functioning of patients with social phobia and had advantage over no treatment condition. These findings are consistent with the findings of Knekt (52) and Blanco (20) regarding the positive effects of psychodynamic psychotherapy on the various functions. Leichsenring (49) obtained an effect size of 1.29 for psychodynamic psychotherapy regarding the improvement in the overall functioning, which is lower than the one we obtained in the present study (ES =1.81).

No significant differences were found between two groups in the number of patients who responded to the treatment $(\mathrm{P}=0.675)$. Response to treatment rate obtained in this study (STDP: $30.76 \%$ ) was smaller than the rates reported by Knijnik(79.3\%) (53) and Bressi (60\%) (54). There was no significant difference between two groups regarding remission rate $(P=1)$. However, the percentage of patients who had remission was higher in this study than the percentage reported by Knijnik (10.3\%) (53).

In MED group, the percentages of patients who had remission and responded to treatment were $18.18 \%$ and $36.11 \%$, respectively, which were lower than the findings of Van Ameringen study (25).

The obtained within group effect size based on Social Phobia Inventory for the psychodynamic psychotherapy $(E S=1.19)$ was almost similar to the ones reported by Leichsenring (ES = 1.39) (49) and Abbass (ES = 1.35) (55). However, the effect size for the psychotherapy group was lower than the one for the medication group ( $E S=1.94$ ). This result was consistent with the findings reported by Anderson (56) and Svartberg (38). In the medical intervention group, the obtained effect size (0.895) based on CGI-S scores was greater than the ones reported in other studies $(25,53,57)$. Effect sizes obtained for both intervention groups were "very large" based on Cohen's scale. Means of repeated evaluations in both medication and psychotherapy groups were not significantly different from each other $(\mathrm{F}=0.219, \mathrm{P}=0.645)$, but both were significantly different from the waiting list $(\mathrm{F}=14.86, \mathrm{P}<001)$.

Apparently, patients who received this therapy (APT) by becoming familiar and controlling their own defense mechanisms (such as pseudo altruism, projection, and idealization) get opportunity to better understand their feelings (mainly their fears) $(37,38)$ toward themselves and others and were able to show more easily their emotions. It also seems that this treatment modified and improved patients' expectations and behaviors (37). These changes led to a reduction in symptoms of social phobia.
Overall, according to the results of this study, short-term psychodynamic psychotherapy is as effective as medication in alleviating the symptoms of social phobia and both interventions have large effect sizes in treatment of social phobia disorder. Thus, APT method of short-term psychodynamic psychotherapy can be considered as an effective method of treatment for social phobia.

\section{Acknowledgements}

The authors sincerely thank Mr Hamid Peyrovi and $\mathrm{Mr}$ Hassan Taghavi from Tehran University Counseling Center for their assistance and cooperation in conducting this research. We also thank Dr Mahmood Dehghani for his valuable help and providing McCullough's treatment manual.

\section{Authors' Contributions}

Mehryar Nader-Mohammadi Moghadam designed the study and managed all stages of the research. MohammadKazem Atef-Vahid helped to design the study and supervised research from beginning to end. Ali-Asghar Asgharnejad-Farid guided short-term dynamic psychotherapy interventions. Amir Shabani directed data gathering and performed statistical analysis. Fahimeh Lavasni provided the protocol of medication and guided pharmacotherapy.

\section{Clinical Trial Registration Code}

IRCT2012103011328N1.

\section{Ethical Committee Code}

$130 / 1720 / \mathrm{d} / 91$

\section{Funding/Support}

This research was funded by Tehran University of Medical Sciences and Mental Health Research Network(MHRN).

\section{Declaration of Interest}

None declared.

\section{References}

1. Lang AJ, Stein MB. Social phobia: prevalence and diagnostic threshold. J Clin Psychiatry. 2001;62 Suppl 1:5-10.

2. Schneier FR, Johnson J, Hornig CD, Liebowitz MR, Weissman MM. Social phobia. Comorbidity and morbidity in an epidemiologic sample. Arch Gen Psychiatry. 1992;49(4):282-8.

3. Magee WJ, Eaton WW, Wittchen HU, McGonagle KA, Kessler RC Agoraphobia, simple phobia, and social phobia in the National Comorbidity Survey. Arch Gen Psychiatry. 1996;53(2):159-68.

4. Wittchen HU, Fehm L. Epidemiology, patterns of comorbidity and associated disabilities of social phobia. Psychiatr Clin North Am. 2001;24(4):617-41.

5. Westenberg HG. The nature of social anxiety disorder. J Clin Psychiatry. 1998;59 Suppl 17:20-6.

6. Yonkers KA, Dyck IR, Keller MB. An eight-year longitudinal comparison of clinical course and characteristics of social phobia among men and women. Psychiatr Serv. 2001;52(5):637-43.

7. Beidel DC. Social anxiety disorder: etiology and early clinical presentation. J Clin Psychiatry. 1998;59 Suppl 17:27-32.

8. Turner SM, Beidel DC, Townsley RM. Social phobia: a comparison of specific and generalized subtypes and avoidant personality disorder.J Abnorm Psychol. 1992;101(2):326-31. 
9. Thyer BA, Parrish RT, Curtis GC, Nesse RM, Cameron OG. Ages of onset of DSM-III anxiety disorders. Compr Psychiatry. 1985;26(2):113-22.

10. Chartier MJ, Hazen AL, Stein MB. Lifetime patterns of social phobia: a retrospective study of the course of social phobia in a nonclinical population. Depress Anxiety. 1998;7(3):113-21.

11. Davidson JR, Hughes DL, George LK, Blazer DG. The epidemiology of social phobia: findings from the Duke Epidemiological Catchment Area Study. Psychol Med. 1993;23(3):709-18.

12. Versiani M, Amrein R, Montgomery SA. Social phobia: long-term treatment outcome and prediction of response--a moclobemide study. Int Clin Psychopharmacol.1997;12(5):239-54.

13. Massion AO, Dyck IR, Shea MT, Phillips KA, Warshaw MG, Keller MB. Personality disorders and time to remission in generalized anxiety disorder, social phobia, and panic disorder. Arch Gen Psychiatry. 2002;59(5):434-40.

14. Merikangas KR, Angst J. Comorbidity and social phobia: evidence from clinical, epidemiologic, and genetic studies. Eur Arch Psychiatry Clin Neurosci.1995;244(6):297-303.

15. Lecrubier Y, Weiller E. Comorbidities in social phobia. Int Clin Psychopharmacol. 1997;12 Suppl 6:S17-21.

16. Wittchen HU, Beloch E. The impact of social phobia on quality of life. Int Clin Psychopharmacol. 1996;11 Suppl 3:15-23.

17. Lipsitz JD, Schneier FR. Social phobia. Epidemiology and cost of illness. Pharmacoeconomics. 2000;18(1):23-32.

18. Weiller E, Bisserbe JC, Boyer P, Lepine JP, Lecrubier Y. Social phobia in general health care: an unrecognised undertreated disabling disorder. Br J Psychiatry. 1996;168(2):169-74.

19. Acarturk C, Smit F, de Graaf R, van Straten A, Ten Have M, Cuijpers P. Economic costs of social phobia: a population-based study. JAffect Disord. 2009;115(3):421-9.

20. Blanco C, Nissenson K, Liebowitz MR. Social anxiety disorder: recent findings in the areas of epidemiology, etiology, and treatment. Curr Psychiatry Rep. 2001;3(4):273-80.

21. Davidson JR. Pharmacotherapy of social phobia. Acta Psychiatr Scand Suppl. 2003(417):65-71.

22. Gould RA, Buckminster S, Pollack MH, Otto MW, Massachusetts LY Cognitive-Behavioral and Pharmacological Treatment for Social Phobia: A Meta-Analysis. Clin Psychol: Sci Practice. 1997;4(4):291-306.

23. Turner SM, Beidel DC, Jacob RG. Social phobia: a comparison of behavior therapy and atenolol.J Consult Clin Psychol.1994;62(2):350-8.

24. Sadock BJ, Sadock VA. Kaplan and Sadock's synopsis of psychiatry: Behavioral sciences/clinical psychiatry.: Lippincott Williams \& Wilkins; 2007.

25. Van Ameringen MA, Lane RM, Walker JR, Bowen RC, Chokka PR, Goldner EM, et al. Sertraline treatment of generalized social phobia: a 20-week, double-blind, placebo-controlled study. Am J Psychiatry. 2001;158(2):275-81.

26. Haug TT, Hellstrom K, Blomhoff S, Humble M, Madsbu HP, Wold JE. The treatment of social phobia in general practice. is exposure therapy feasible? Fam Pract. 2000;17(2):114-8.

27. Katzelnick DJ, Kobak KA, Greist JH, Jefferson JW, Mantle JM, Serlin RC. Sertraline for social phobia: a double-blind, placebo-controlled crossover study. Am J Psychiatry. 1995;152(9):1368-71.

28. Munjack DJ, Flowers C, Eagan TV. Sertraline in social phobia.Anxiety. 1994;1(4):196-8.

29. Czepowicz VD, Johnson MR, Lydiard RB, Emmanuel NP, Ware MR, Mintzer OB, et al. Sertraline in social phobia. J Clin Psychopharmacol. 1995;15(5):372-3.

30. Rapee RM. Group treatment of children with anxiety disorders: Outcome and predictors of treatment response. Aust J Psychol. 2000;52(3):125-9.

31. Zaider TI, Heimberg RG. Non-pharmacologic treatments for social anxiety disorder. Acta Psychiatr Scand Suppl. 2003(417):72-84.

32. Davidson JR, Foa EB, Huppert JD, Keefe FJ, Franklin ME, Compton IS, et al. Fluoxetine, comprehensive cognitive behavioral therapy, and placebo in generalized social phobia. Arch Gen Psychiatry. 2004;61(10):1005-13.

33. Alstrom JE, Nordlund CL, Persson G, Harding M, Ljungqvist C. Effects of four treatment methods on social phobic patients not suitable for insight-oriented psychotherapy. Acta Psychiatr Scand. 1984;70(2):97-110.

34. Fonagy P, Roth A, Higgitt A. Psychodynamic psychotherapies: evidence-based practice and clinical wisdom. Bull MenningerClin.
2005;69(1):1-58

35. Gabbard G, Levy RA, Ablon JS. Handbook of evidence-based psychodynamic psychotherapy: Bridging the gap between science and practice.: Humana Press; 2008.

36. Vaillant LMC. Changing character: Short-term anxiety-regulating psychotherapy for restructuring defenses, affects, and attachment.: Basic Books; 1997.

37. McCullough L, Kuhn N, Andrews S, Kaplan A, Wolf J, Hurley CL. Treating affect phobia: A manual for short-term dynamic psychotherapy:: Guilford Press; 2003.

38. Svartberg M, Stiles TC, Seltzer MH. Randomized, controlled trial of the effectiveness of short-term dynamic psychotherapy and cognitive therapy for cluster C personality disorders. Am J Psychiatry. 2004;161(5):810-7.

39. Winston A, Laikin M, Pollack J, Samstag LW, McCullough L, Muran JC. Short-term psychotherapy of personality disorders. Am J Psychiatry. 1994;151(2):190-4.

40. Dehghani M, Atef-Vahid MK, Gharaee B. Efficacy of short-term anxiety-regulating psychotherapy on love trauma syndrome. Iran J Psychiatry Behav Sci. 2011;5(2):18-25.

41. Dornelas EA, Ferrand J, Stepnowski R, Barbagallo J, McCullough L. A pilot study of affect-focused psychotherapy for antepartum depression.J Psychother Integr. 2010;20(4):364.

42. First M, Spitzer R, Gibbon M, Williams J. Structured clinical interview for Axis I DSM-IV disorders.New York: Biometrics Research.; 1994

43. Connor KM, Davidson JR, Churchill LE, Sherwood A, Foa E, Weisler RH. Psychometric properties of the Social Phobia Inventory (SPIN). New self-rating scale. Br J Psychiatry. 2000;176:379-86.

44. Zaider TI, Heimberg RG, Fresco DM, Schneier FR, Liebowitz MR. Evaluation of the clinical global impression scale among individuals with social anxiety disorder. Psychol Med. 2003;33(4):611-22.

45. Startup M, Jackson MC, Bendix S. The concurrent validity of the Global Assessment of Functioning (GAF). Br J Clin Psychol. 2002;41(Pt 4):417-22.

46. Bandelow B. Defining response and remission in anxiety disorders: toward an integrated approach. CNS Spectr. 2006;11(10 Suppl 12):21-8.

47. Bogels SM, Voncken MJ, de Vries K. Interpretation and judgmental biases in social phobia. Behav Res Ther. 2003;41(12):1481-8.

48. Crits-Christoph P. The efficacy of brief dynamic psychotherapy: a meta-analysis. Am J Psychiatry. 1992;149(2):151-8.

49. Leichsenring F, Rabung S, Leibing E. The efficacy of short-term psychodynamic psychotherapy in specific psychiatric disorders: a meta-analysis. Arch Gen Psychiatry. 2004;61(12):1208-16.

50. Leichsenring F, Leibing E. Psychodynamic psychotherapy: a systematic review of techniques, indications and empirical evidence. Psychol Psychother. 2007;80(Pt 2):217-28.

51. Lewis AJ, Dennerstein M, Gibbs PM. Short-term psychodynamic psychotherapy: review of recent process and outcome studies. Aust NZ J Psychiatry. 2008;42(6):445-55.

52. Knekt P, Lindfors O, Laaksonen MA, Renlund C, Haaramo P, Harkanen T, et al. Quasi-experimental study on the effectiveness of psychoanalysis, long-term and short-term psychotherapy on psychiatric symptoms, work ability and functional capacity during a 5-year follow-up. J Affect Disord. 2011;132(1-2):37-47.

53. Knijnik DZ, Blanco C, Salum GA, Moraes CU, Mombach C, Almeida E, et al. A pilot study of clonazepam versus psychodynamic group therapy plus clonazepam in the treatment of generalized social anxiety disorder. Eur Psychiatry. 2008;23(8):567-74.

54. Bressi C, Porcellana M, Marinaccio PM, Nocito EP, Magri L. Shortterm psychodynamic psychotherapy versus treatment as usual for depressive and anxiety disorders: a randomized clinical trial of efficacy. J Nerv Ment Dis. 2010;198(9):647-52.

55. Abbass AA, Hancock JT, Henderson J, Kisely S. Short-term psychodynamic psychotherapies for common mental disorders. Cochrane Database Syst Rev. 2006(4).

56. Anderson EM, Lambert MJ. Short-term dynamically oriented psychotherapy: A review and meta-analysis. Clin Psychol Rev. 1995;15(6):503-14

57. Liebowitz MR, DeMartinis NA, Weihs K, Londborg PD, Smith WT, Chung $\mathrm{H}$, et al. Efficacy of sertraline in severe generalized social anxiety disorder: results of a double-blind, placebo-controlled study. J Clin Psychiatry. 2003;64(7):785-92. 